\title{
Implicit and Explicit Memory for Shape, Body Weight, and Food-Related Words in Patients With Anorexia Nervosa and Nondieting Controls
}

\author{
Dirk Hermans \\ University of Leuven
}

\author{
Guido Pieters \\ University Centre Sint-Jozef
}

\author{
Paul Eelen \\ University of Leuven
}

\begin{abstract}
Twelve patients with anorexia nervosa and 12 control participants watched a series of 64 words. There were 4 word types: anorexia related, positive, negative, and neutral. The last 3 types were anorexia unrelated. Anorexia-related words had the same affective valence as the neutral control words. Next, the participants completed an explicit memory test (cued recall) and an implicit memory test (word stem completion). Results showed a strong explicit memory bias for anorexia-related words for patients with anorexia nervosa but not for nondieting controls. There was no evidence for a similar bias in implicit memory. Results are discussed in the context of cognitive biases in psychopathology.
\end{abstract}

Clinical experience suggests that patients with anorexia nervosa are extremely preoccupied with thoughts of food, body shape, and weight. This is reflected in cognitive theories of anorexia nervosa (e.g., Garner \& Bemis, 1982), which suggest that self-related memory schemata represent the core psychopathology of anorexia (Vitousek \& Hollon, 1990) and that these schemata and related thoughts might have a causal role in the etiology of this eating disorder. Against this background, the cognitive model proposed by Beck (1976; Beck, Rush, Shaw, \& Emery, 1979), which originated from the study of depression and anxiety, has been applied to anorexia nervosa (Butow, Beumont, \& Touyz, 1993; Garner \& Bemis, 1982). According to Vitousek and Hollon (1990), patients with anorexia nervosa develop organized cognitive structures around anorexia-related issues such as weight. And just as these schemata have been implicated in the maintenance of depressive and anxiety disorders, Vitousek and Hollon (1990, p. 192) suggested that they may play a role in supporting the maladaptive behavior associ-

Dirk Hermans, postdoctoral researcher for the Fund for Scientific Research (Flanders, Belgium), Department of Psychology, University of Leuven, Leuven, Belgium; Guido Pieters, University Psychiatric Centre, University Centre (U.C.) Sint-Jozef, Kortenberg, Belgium; Paul Eelen, Department of Psychology, University of Leuven, Leuven, Belgium.

We thank Paula Niedenthal, Walter Vandereycken, the members of Sint-Lukas (U.C. Sint-Jozef, Kortenberg, Belgium), and the members of the Centre for Learning Theories and Behaviour Therapy (Department of Psychology, University of Leuven, Belgium) for their help at various stages of the study and their helpful comments on an earlier version of the article.

Correspondence concerning this article should be addressed to Dirk Hermans, Department of Psychology, University of Leuven, Tiensestraat 102, B-3000 Leuven, Belgium. Electronic mail may be sent to Dirk.Hermans@psy.kuleuven.ac.be. ated with eating disorders. Such weight-related self-schemata might produce systematic errors in the processing of anorexiarelated information through processes such as selective attention, confirmatory bias, and illusory correlations. So, schematic processing might act to prolong symptoms in a relatively automatic fashion.

A limited number of studies have tried to unveil the content and nature of these schemata by using self-report questionnaires (Clark, Feldman, \& Channon, 1989), concurrent verbalization (Cooper \& Fairburn, 1992b), and repertory grids (Butow et al., 1993). Typically, these studies have demonstrated more negative thoughts related to eating, weight, and shape in groups of patients with anorexia nervosa than in nondieting control groups. These data seem to be important, not only because they have been an impetus for the clinical use of cognitively oriented self-report instruments, such as the Eating Disorders Inventory (Garner, Olmsted, \& Polivy, 1983), the Eating Attitudes Test (Garner \& Garfinkel, 1979), and the Anorectic Cognitions Questionnaire (Mizes \& Klesges, 1987), but also because these data are often taken as support for the implementation of cognitive therapy as the treatment of choice for eating disorders.

However, a major problem with methods such as repertory grids, concurrent verbalization, and questionnaires is that they rely on self-report, which can be easily biased by demand characteristics. Moreover, denial and distortion in self-report are prevalent in individuals with eating disorders (Tucker \& Schlundt, 1995; Vitousek, Daly, \& Heiser, 1991). Finally, these instruments cover only one aspect of human cognitive processing (i.e., conscious verbalization) and are limited in their access to processes and representations that take place or exist outside verbal awareness (Power, 1991). In this sense, Clark et al. (1989) argued that it might be more fruitful to look further than the self-statement level and to investigate the preconscious processes. 
In fact, during the last decade, traditional experimental cognitive research methods such as Stroop tasks, priming tasks, and memory tasks have been successfully modified to study the cognitive structures and lower levels of information processing in emotional and other psychiatric disorders (Williams, Watts, MacLeod, \& Mathews, 1988). A large number of studies have investigated selective attention and memory for emotionally relevant material in both anxious and depressed individuals (for an overview, see MacLeod, 1990; Mathews \& MacLeod, 1994). The general conclusion of this research is that mood-congruent information is given priority, as predicted by memory-based theories of emotion (Beck et al., 1979; Bower, 1981). However, there have been some striking exceptions to this general rule. Selective processing of mood-congruent information has recurrently been established in anxious persons with Stroop or attentional probe tasks (e.g., MacLeod, Mathews, \& Tata, 1986; Mathews \& MacLeod, 1985) but not within tests of recall or recognition (e.g., Mogg, Mathews, \& Weinman, 1987). Depressed persons, on the other hand, have frequently shown a relative memory advantage for emotionally negative stimuli (e.g., Denny \& Hunt, 1992), but they show less evidence of a depression-linked bias in attentional processing (MacLeod et al., 1986; Mogg et al., 1991).

This apparent dissociation poses a problem for Beck's (Beck et al., 1979) schema theory and Bower's (1981) associative network theory as they predict mood-congruent biases in all aspects of processing, including attention, encoding, judgment, and retrieval. Williams et al. (1988), however, put forward a different theoretical account to explain these discordant findings, using Graf and Mandler's (1984) distinction between integration and elaboration. Integration (priming) is regarded as a relatively automatic process and refers to the strengthening of the memory representation of a stimulus when it is processed, consequently rendering it more accessible. For example, higher accessibility or integration makes a word come to mind more easily when only some of its components or features (e,g., the initial letters of a word) are presented. This is tested in implicit memory tasks such as the word completion task. Elaboration, on the other hand, refers to a more strategic process, which consists of the activation of a representation in relation to other associated representations to form new relationships between them and to activate old relationships (Williams et al., 1988, p. 170). Stronger elaboration makes a memory concept more retrievable as more paths or retrieval cues can be used for recall.

Williams et al. (1988) subsequently hypothesized that tests such as perceptual threshold tasks, Stroop tasks, and attentional probe tasks, which are indicative of selective processing in anxious persons, typically assess stimulus accessibility. Elaboration of memory concepts, on the other hand, is assessed by recall and recognition tasks (explicit memory) that provide standard observations for selective processing of mood-related stimuli in persons with depression. Hence, anxiety seems to be associated with a greater accessibility of mood-related items, whereas depression is supposed to involve a relatively larger retrievability of negative concepts. Subsequent studies (Denny \& Hunt, 1992; MacLeod \& McLaughlin, 1995; Mathews, Mogg, May, \& Eysenck, 1989; Richards \& French, 1991; Watkins, Mathews, Williamson, \& Fuller, 1992) have been largely supportive of
Williams et al.'s ( 1988) model (but see Bradley, Mogg, \& Williams, 1995; Mathews, Mogg, Kentish, \& Eysenck, 1995).

Because it was felt that the experimental cognitive methodologies would prove fruitful (Channon, Hemsley, \& de Silva, 1988), a number of researchers have used the Stroop task in the investigation of selective processing of material related to food and body size in patients with anorexia nervosa (Ben-Tovim \& Walker, 1991; Ben-Tovim, Walker, Fok, \& Yap, 1989; Channon et al., 1988; Cooper \& Fairburn, 1992a; Green, McKenna, \& de Silva, 1994; Long, Hinton, \& Gillespie, 1994; Perpiñá, Hemsley, Treasure, \& de Silva, 1993; Walker, Ben-Tovim, Jones, \& Bachok, 1992; Walker, Ben-Tovim, Paddick, \& McNamara, 1995). In this modified version of the Stroop task (Stroop, 1935), patients with anorexia nervosa are asked to name, as quickly as possible, the colors in which a series of anorexiarelated words (e.g., fat, diet, hips) or neutral words (e.g., ocean, clock) are printed. The studies show that in comparison with neutral control words, the color naming of anorexia-related words is inhibited for patients with anorexia nervosa but not for the control group. This selective processing of information related to eating, weight, and shape has been interpreted as evidence for the existence and operation of eating disordered schemata in persons with anorexia nervosa (Vitousek \& Hollon, 1990). Moreover, according to Walker et al. (1992), these measures avoid the demand characteristics that bedevil self-report and interview measures (for a more detailed discussion, see Tucker \& Schlundt, 1995).

Consequently, it can be argued that the results of the modified Stroop tasks in patients with anorexia nervosa indicate that memory concepts related to food, body weight, and shape are more accessible, and thus more easily primed. There is, however, less robust evidence for their retrievability. In a study by King, Polivy, and Herman (1991), patients with anorexia nervosa recalled more food- and weight-related items than neutral items. But in a study by Channon et al. (1988), recognition memory for previously presented food- or weight-related words did not differ for patients with anorexia nervosa and controls. Finally, using a free-recall task, Sebastian, Williamson, and Blouin (1996) found that a group of persons diagnosed with an eating disorder remembered relatively more fatness-related words than control words. But, their clinical sample consisted of patients with different types of diagnoses (anorexia nervosa, bulimia nervosa, and eating disorder not otherwise specified), and they did not report whether this memory bias was still present when only the patients with anorexia nervosa were taken into account.

A major problem with all studies reported here using Stroop or memory tasks is that they did not control for the affective impact of the experimental stimuli. In fact, it could well be argued that anorexia-related words are threatening for patients with anorexia nervosa but not for nonclinical controls. Clark et al.'s (1989) sample of patients with anorexia nervosa, for example, were significantly more state anxious than the nonclinical sample. Hence, inhibited response latencies toward food-, shape-, and weight-related words in a modified Stroop task for patients with anorexia nervosa could be no more than a standard observation of selective processing of threat-related concepts in anxious individuals. Vitousek and Hollon (1990, p. 201 ) therefore argued that if the Stroop test is to offer more than an indirect means of verifying that patients really are upset about 
the stimuli, future studies may wish to demonstrate that target stimuli not only produce anxiety in the participants but are also actually represented within cognitive structures in an organized fashion.

In the present study, we assessed both accessibility and retrievability for anorexia-related and anorexia-unrelated concepts for patients with anorexia nervosa and nondieting controls, using tests of implicit memory (word completion) and explicit memory (cued recall). If anorexia nervosa is indeed positively associated with a higher accessibility of anorexia-related words, as suggested by the Stroop tasks, this should be reflected in more word stem completions for these anorexia-related words as compared with anorexia-unrelated words. Cued-recall scores, as an index of retrievability, give an indication of the elaboration of anorectic memory schemata. To prevent the confounding of the affective valence and the anorexia relatedness of the stimulus words, we compared anorexia-related words with anorexia-unrelated words with a similar affective rating.

\section{Method}

\section{Participants}

All participants in the experimental group $(N=12)$ were inpatients attending an eating disorder rehabilitation program at a university psychiatric center (University Centre Sint-Jozef, Kortenberg, Belgium). All were diagnosed as anorexia nervosa patients according to the criteria of the Diagnostic and Statistical Manual of Mental Disorders (3rd ed., rev.; American Psychiatric Association, 1987). None of them were currently fasting. Patients who showed a comorbidity of bulimia nervosa were excluded from this study. The control group consisted of 12 nondieting volunteers, with no known history of psychiatric treatment. To match the control group's level of education as closely as possible to that of the experimental group, we chose individuals with different educational levels (junior or senior high school, undergraduate, and graduate) as controls. ${ }^{1}$ Both groups were matched for age and sex. Additional characteristics of participants are given in Table 1 . None of the participants were informed of the purpose of the study.

\section{Stimuli}

To prevent a confounding between the anorexia relatedness and the affective value of the stimulus words (see introduction), we compared

Table 1

Characteristics of Participant Groups: Means and Standard Deviations (in Parentheses)

\begin{tabular}{lccc}
\hline \multicolumn{1}{c}{ Measure } & $\begin{array}{c}\text { Anorectic } \\
\text { patients }\end{array}$ & $\begin{array}{c}\text { Nondieting } \\
\text { controls }\end{array}$ & $t(22)$ \\
\hline STAI State & $45.25(10.89)$ & $34.28(14.92)$ & 1.99 \\
STAI Trait & $52.58(9.49)$ & $42.75(12.01)$ & $2.25^{*}$ \\
WAIS Substitution & $62.08(6.97)$ & $64.33(10.91)$ & -0.60 \\
Sex ratio (M/F) & $1 / 11$ & $1 / 11$ & 0 \\
Age (years) & $21.08(6.54)$ & $24.67(10.35)$ & -1.01 \\
Weight (kg) & $42.75(9.18)$ & $64.08(9.33)$ & $-5.65^{* *}$ \\
Height (cm) & $167.58(9.38)$ & $168.92(4.99)$ & -0.44 \\
BMI & $15.04(1.87)$ & $22.50(3.41)$ & $-6.64 * *$ \\
\hline
\end{tabular}

Note. $\quad$ STAI $=$ Spielberger State - Trait Inventory; WAIS $=$ Wechsler Adult Intelligence Scale; $M=$ male; $F=$ female; $B M I=$ body mass index.

${ }^{*} p<.05 . \quad{ }^{* *} p<.001$. similarly valenced anorexia-related and anorexia-unrelated words. The composition of these experimental word sets was initially based on a larger set of 200 Dutch nouns, selected from Hermans and De Houwer (1994), to which words related to shape, body weight, and food were added. These nouns were rated for anorexia relatedness by seven experts in the field of eating disorders on 10-point Visual Analogue Scales (VAS), from $1=$ not at all related to anorexia nervosa to $10=v e r y$ related to anorexia nervosa. Additionally, these words were rated by a separate group of eight independent judges for the positive-negative dimension (Affectivity), from $1=$ very negative to $10=$ very positive. On the basis of these ratings, equal samples $(N=24)$ of anorexiarelated (AR), positive (P), negative $(N)$, and neutral $(N t)$ words were selected. AR words differed significantly from the three other word types $(\mathrm{P}, \mathrm{N}$, and $\mathrm{Nt}$ ) for anorexia relatedness, $t(46)>39, p<.001$, for all comparisons. But we took special care that AR words did not differ from $\mathrm{Nt}$ control words with respect to their affective valence, $t(46)=$ $0.304, p=.76$. This was done to create a set of words that differed from the Nt control words in the sense that they were highly relevant with respect to the pathology of anorexia nervosa but did not differ from the Nt control words pertaining to their affective valence. Such a set of words allows us to disentangle the effect of anorexia relatedness from possible effects of the affective qualities of the stimulus material. All other comparisons between the four word types, pertaining to affective valence, reached significance, $t(46)<6.1, p<.001$ (means are presented in Table 2). ${ }^{2}$

The four word types were also matched for word length and for objective word frequency according to the Uit den Bogaart (1975) norms. Each of the 96 words had a unique three-letter stem, and for each word there was at least one other word (which was not presented to the participants) that had the same three-letter stem and a higher objective word frequency score (Uit den Bogaart, 1975) than that of the stimulus word. Finally, using the Revised Wordlist of the Dutch Language (Herziene woordenlijst van de Nederlandse taal, 1990), there was an equal number of alternative words that started with the same three-letter stem for the four word types.

From this set of 96 words, three parallel sets of words (A, B, and, C) were created, each containing $8 \mathrm{AR}$ words, $8 \mathrm{P}$ words, $8 \mathrm{~N}$ words, and $8 \mathrm{Nt}$ words. Also, these three sets were matched for affective value, anorexia relatedness, word frequency, number of letters, and number of available stem completions. The stimulus words are shown in the Appendix.

\section{Apparatus}

All stimuli were presented in white uppercase letters, in the center of an all-black background, by an IBM-compatible 386 computer with

\footnotetext{
' For both groups, 1 participant completed junior high school. Nine participants from the anorectic group and 7 participants from the control group completed senior high school. Two participants from the anorectic group and 4 participants from the control group completed higher education (anorectic group: 2 university degrees; control group: 2 college degrees and 2 university degrees).

${ }^{2}$ Given that Nt words do differ from AR words for anorexia relatedness but not for affective valence, they can be considered as the best baseline to assess explicit and implicit memory bias for AR words. Nevertheless, $\mathrm{P}$ and $\mathrm{N}$ words are included in the final procedure. Not only can they serve as filler items, but in the case that the research participants should give relatively more positive or negative ratings for the AR words as compared with the Nt words during the stimulus presentation phase (pleasantness ratings; see Procedure section), additional analyses could be performed with $\mathrm{P}$ or $\mathrm{N}$ words as a more appropriate baseline.
} 
Table 2

Means and Significance for the Four Word Types

\begin{tabular}{lccccc}
\hline \multicolumn{1}{c}{ Measure } & $\begin{array}{c}\text { Anorexia } \\
\text { related }\end{array}$ & Positive & Negative & Neutral & $F(3,92)$ \\
\hline AN relatedness & 9.31 & 1.67 & 1.48 & 1.30 & $1.118^{* * *}$ \\
Affective rating & 5.08 & 7.25 & 2.77 & 5.18 & $64^{* *}$ \\
Word length & 6.92 & 7.21 & 6.71 & 6.96 & $<1$ \\
Word frequency & 11.37 & 10.00 & 5.54 & 8.92 & $<1$ \\
Word stem & 198 & 257 & 154 & 168 & $<1$ \\
\hline
\end{tabular}

Note. Word length is expressed as mean number of letters; word stem refers to the number of words starting with the same three-letter stem. AN = anorexia nervosa.

$* * p<.001$.

a monochrome screen. Letters had a constant lettering height of $12 \mathrm{~mm}$ and were approximately $7 \mathrm{~mm}$ in breadth.

The three parallel word sets were used to prepare three versions of both memory tests. Each version of the cued recall test consisted of the three-letter stems from one set of words (i.e., A, B, or C). For the word completion test, the three-letters stems from two sets of words (i.e., $\mathrm{AB}, \mathrm{BC}$, or $\mathrm{AC}$ ) were combined. The stems were listed randomly on a response form, but no more than two consecutive stems were of the same word type.

\section{Procedure}

During the encoding task, participants were presented with two sets of the stimulus words ( $\mathrm{AB}, \mathrm{AC}$, or $\mathrm{BC}$ ). Participants were seen individually and were informed that they were taking part in a study on imagination. They were told that words would be presented on the computer screen one at a time and that they were to imagine a scene involving themselves and the presented word. They could think of past, present, or possible future scenes, which could be either authentic or entirely fantasized, as long as the imagination involved themselves and the presented stimulus word (self-referent encoding task). They were encouraged to build up the imagination during the $10-\mathrm{s}$ presentation of the words. Four practice trials preceded the two sets of 32 stimulus words. The choice of the sets $(\mathrm{AB}, \mathrm{AC}, \mathrm{BC})$ was determined according to the balanced design (Mathews et al., 1989).

Words were presented in a randomized order that was different for each participant. After the 10-s presentation, the word was replaced by a $185-\mathrm{mm}$ horizontal bar, labeled very unpleasant $(-5)$ at one end and very pleasant $(+5)$ at the other. Participants were asked to indicate their rating of the imagined word, adjusting the arrow to the desired position on this 11 -point VAS scale by means of the computer mouse. We emphasized that the scale represented a continuum, so that it was not necessary to use the 11 anchor points. When the response was recorded by the computer, the next trial was initiated after an intertrial interval of $4 \mathrm{~s}$.

Following the encoding task, participants performed a brief nonverbal filler task (the Substitution subtest of the Wechsler Adult Intelligence Scale [WAIS]; Stinissen, Willems, Coetsier, \& Hulsman, 1970). They then carried out both memory tasks. Half of the participants in each group started with the word completion task, the other half with the cued-recall task. The latter task consisted of word stems from one of the two word sets presented during the acquisition phase. Word stems in the word completion task comprised both the other previously presented (primed) word set and the words from the set that was not presented earlier (unprimed words). Test order and word sets used in each task were determined according to the balanced design (see Mathews et al., 1989).

For the word completion task, participants were handed the appropriate response sheet and were instructed to complete the three-letter stems with the first word that came into their mind, beginning with the letters printed on the response form. Participants were told to work through the stems in the order in which the items were listed. There was no time limit, but all participants finished the task within 5 min. This test assessed implicit memory for half of the words presented during the encoding task (primed words) and to an equivalent set of words that were not previously presented (unprimed words).

For the cued-recall task, which assessed explicit memory for the remaining half of the words presented in the encoding task, participants were provided with the corresponding response sheet and were asked to complete the three-letter stems to words they had seen earlier on the computer screen during the imagination task. They were instructed to complete each stem by recalling these previously presented words and writing down the missing letters. They were given $5 \mathrm{~min}$ to work through the list in any order. They were instructed to give their best guess if doubtful about a specific word stem.

Finally, all participants completed both state and trait parts of the Spielberger State-Trait Anxiety Inventory (STAI; Hermans, 1994; Spielberger, Gorsuch, Lushene, Vagg, \& Jacobs, 1983; Van der Ploeg, Defares, \& Spielberger, 1980 [Dutch adaptation]) and the first part of the Eating Disorder Evaluation Scale (Vandereycken, 1993) concerning social status, weight and weight fluctuations, body mass index (BMI), and dieting.

Results

\section{Participant Characteristics}

The experimental group and the control group did not differ in mean age, height, sex ratio, WAIS Substitution scores, and state anxiety. A priori $t$ tests for independent samples (see Table 1) revealed that the patients with anorexia nervosa rated themselves as more trait anxious and showed a significantly smaller weight and BMI.

\section{Pleasantness Ratings}

Pleasantness ratings indicated by the participants on the 185 mm bar were recorded by the computer as integers ranging from -250 (very unpleasant) to +250 (very pleasant). To assess the affective impact of the four word types for the patients with anorexia nervosa as well as the control group, we computed simple main effects of word type (AR, P, N, Nt) on these affective ratings. For the patients with anorexia nervosa, there was a strong effect of word type, $F(3,66)=28.3, M S E=$ 2,327.55, $p<.000001$. A posteriori contrasts (Tukey's honestly 
significant difference [HSD], $p<.05$ ) revealed significantly lower ratings for $\mathrm{N}$ words $\left(M_{\mathrm{N}}=-87.5\right)$, as compared with AR words $\left(M_{\mathrm{AR}}=-16.3\right), \mathrm{P}$ words $\left(M_{\mathrm{P}}=88.9\right)$, and Nt words $\left(M_{\mathrm{Nt}}=25.8\right)$. Similarly, affective ratings for $\mathrm{P}$ words were significantly higher, as compared with each of the three other word types. The difference between AR words and Nt words was, however, not significant. For the control group, a similar pattern of results emerged, $F(3,66)=88.7, M S E=1,418.30$, $p<.000001\left(M_{\mathrm{AR}}=12.5, M_{\mathrm{P}}=125.8, M_{\mathrm{N}}=121.1\right.$, and $M_{\mathrm{Nt}}$ $=40.5$ ). A posteriori contrasts (Tukey HSD) again revealed significant differences for all comparisons, except for AR and $\mathrm{Nt}$ words, which did not differ. Finally, a posteriori contrasts showed no significant differences between the anorectic group and the control group for any of the four word types. Given these ratings and the ratings provided by the two independent groups of judges (see Stimuli section under Method), the Nt words can be considered as the most appropriate baseline to assess explicit and implicit memory for AR words.

\section{Cued-Recall Test (Explicit Memory)}

For each participant, the number of recalled words was computed for each of the four word types. Words were considered correct only if they appeared exactly in the same form during the encoding task. Changes in the suffix of the word were scored as incorrect. On the basis of this strict scoring method (Mathews et al., 1989), a priori contrasts (two-tailed) were calculated for all relevant comparisons (see Figure 1). As predicted, patients with anorexia nervosa recalled more AR words $(M=6.33)$ than $\mathrm{P}$ words $(M=4.25), F(1,22)=22.99, M S E=1.13, p$ $<.001 ; \mathrm{N}$ words $(M=4.67), F(1,22)=12.45, M S E=1.34$, $p<.002$; or Nt words $(M=3.83), F(1,22)=17.62, M S E$ $=2.12, p<.001$. Cued-recall scores for $\mathrm{P}, \mathrm{N}$, and $\mathrm{Nt}$ words did not differ: for each comparison, $F(1,22)<2.02$, $n s$. For the control group, on the other hand, no memory advantage was observed for the AR words $(M=4.08)$, as compared with $\mathrm{P}$ words $(M=4.17, F<1), \mathrm{N}$ words $(M=3.83, F<1)$, or Nt words $(M=3.42), F(1,22)=1.25, n s$. Also, no differences were observed between the cued-recall scores for $\mathrm{P}, \mathrm{N}$, and $\mathrm{Nt}$ words: for each comparison, $F(1,22)<1.4$, $n$ s.

This pattern of results was confirmed by a subsequent 2 (group: anorectic vs. control) $\times 4$ (word type: AR vs. P vs. $\mathrm{N}$ vs. Nt) analysis of variance (ANOVA), which showed a significant Group $\times$ Word Type interaction, $F(3,48)=3.84, M S E=$ $1.69, p<.02$. Besides this crucial interaction, the two main effects of group and word type were significant. Overall, patients with anorexia nervosa remembered more words than the control group, $F(1,22)=5.37, M S E=3.59, p<.05$, and AR words were remembered better than $\mathrm{P}, \mathrm{N}$, or $\mathrm{Nt}$ words, $F(3,66)=$ $6.11, M S E=1.69, p<.001$.

Finally, correlations were calculated between an index of explicit memory bias for the group of patients with anorexia nervosa (number of recalled AR words minus number of recalled Nt words) and scores for the available participant characteristics (STAI state, STAI trait, WAIS substitution, age, weight, height, and BMI). None of these correlations were significant.

\section{Word Completion Test (Implicit Memory)}

Completions were scored as correct if they perfectly matched the word from the related word set. Mean primed and unprimed word completion scores for each of the four word types were computed for both groups (see Table 3 ). To test the hypothesis that anorexia-related concepts are more easily activated than unrelated concepts in patients with anorexia nervosa but not in nondieting controls, we computed a priori contrasts (two-tailed) for both groups between the four word types. This was done for primed and unprimed words separately. This a priori analysis revealed that patients with anorexia nervosa completed significantly more word stems for primed AR words than for primed Nt words, $F(1,22)=8.19, M S E=0.86, p<.01$. The related comparison for unprimed words was, however, not significant,

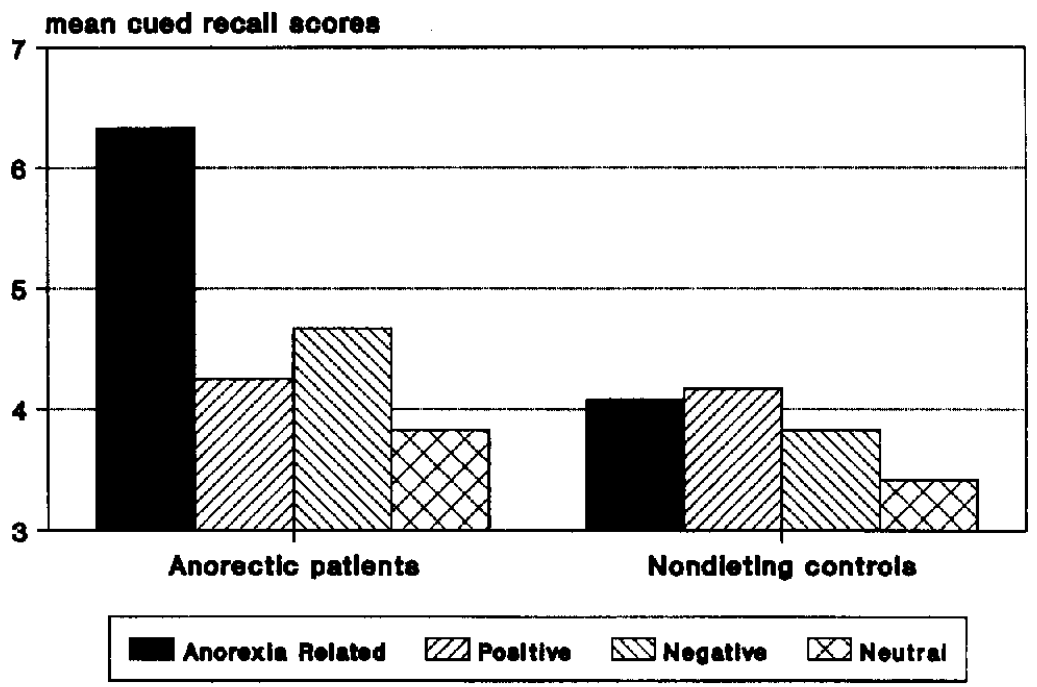

Figure 1. Mean cued-recall scores for anorexia-related, positive, negative, and neutral words for patients with anorexia nervosa and nondieting controls ( $\operatorname{minimum}=0$; maximum $=8$ ). 
Table 3

Mean Word Completion Scores for Anorexia-Related, Positive, Negative, and Neutral Words for Patients With Anorexia Nervosa and Nondieting Controls

\begin{tabular}{lcccc}
\hline \multicolumn{1}{c}{ Measure } & $\begin{array}{c}\text { Anorexia } \\
\text { related }\end{array}$ & Positive & Negative & Neutral \\
\hline $\begin{array}{l}\text { Word completion (primed) } \\
\quad \text { Anorectics }\end{array}$ & 2.92 & & & \\
$\quad \begin{array}{l}\text { Controls } \\
\text { Word completion (unprimed) }\end{array}$ & 2.25 & 2.92 & 2.75 & 1.83 \\
$\quad$ Anorectics & 1.33 & 2.17 & 2.33 & 1.67 \\
$\quad$ Controls & 1.08 & 1.25 & 1.00 & 0.75 \\
Primed/unprimed difference & & 0.92 & 1.17 & 0.75 \\
$\quad$ Anorectics & 1.58 & 1.67 & 1.75 & 1.08 \\
Controls & 1.17 & 1.25 & 1.17 & 0.92 \\
\hline
\end{tabular}

Note. $\quad$ Minimum $=0 ;$ maximum $=8$.

$F(1,22)=2.06, M S E=0.99, p=.16$. For the nondieting controls, none of the a priori comparisons between the four word types, for primed as well as unprimed words, reached the level of significance. This data pattern suggests an implicit memory bias for AR words in patients with anorexia nervosa but not in nondieting controls. Although performance on the primed word stems can be considered as an index of temporal activation (priming or integration), the latter effect can only be estimated correctly if compared with a baseline of word completion in the absence of recent exposure to the relevant stimuli (unprimed condition). For this reason, difference scores were calculated for each of the word types by subtracting the performance on the unprimed word stems from the performance on the primed word stems (see Table 3). A priori contrasts on these difference scores revealed no significant benefit of recent exposure for AR words as compared with Nt words: anorectic group, $F(1,22)=1.04, M S E=1.44, p=.32$, and control group, $F(1,22)<1, M S E=1.44$. Therefore, we cannot conclude that an implicit memory bias for anorexia-related materials was present in the anorectic group. Similarly, none of the other a priori contrasts based on the difference scores reached significance.

Finally, we conducted a 2 (group: anorectic vs. control) $\times$ (priming condition: primed vs. unprimed) $\times 4$ (word type: AR vs. P vs. N vs. Nt) ANOVA with repeated measures for the last two variables. The crucial Group $\times$ Priming Condition $\times$ Word Type interaction was nonsignificant, $F(3,66)<1$. A significant main effect was found for priming condition, $F(1,22)=39.75$, $M S E=2.11, p<.00001$. Regardless of group, participants completed more word stems for words to which they had recently been exposed ( $M=2.35$, primed condition) than for unprimed words ( $M=1.03$ ). The only other significant effect was a main effect of word type, $F(3,66)=3.37, M S E=1.26$, $p<.05$. Regardless of group and priming condition, there were more correct word stem completions for AR words ( $M=1.9)$ than for Nt words ( $M=1.25$, Tukey HSD). None of the other comparisons reached significance $\left(M_{\mathrm{P}}=1.81 ; M_{\mathrm{N}}=1.81\right)$.

\section{Discussion}

In this study, implicit and explicit memory for AR words and anorexia-unrelated $\mathrm{P}, \mathrm{N}$, and $\mathrm{Nt}$ words were assessed for patients with anorexia nervosa and a nondieting control group following a self-referent encoding task. Ratings provided by an independent group of judges with no known history of eating disorders showed that the selected AR words did not differ from unrelated $\mathrm{Nt}$ words on the affective-evaluative dimension. This was confirmed by the participants' overall affective ratings during the encoding task. Hence, because there was no confounding between anorexia relatedness and affective value, the unrelated $\mathrm{Nt}$ control words form an appropriate baseline for testing implicit and explicit memory bias for AR concepts in persons with anorexia nervosa. As discussed earlier, such confounding might have been present in previous attentional and memory studies in persons with an eating disorder.

Cued-recall scores provide clear evidence that patients with anorexia nervosa show an explicit bias favoring anorexia-related stimulus material. It is also important to note that although the participants with anorexia nervosa were somewhat more trait anxious, no selective recall was observed for anorexia-unrelated negative words in this group. Moreover, the observed explicit memory bias did not correlate with the measures of state and trait anxiety, which provides further evidence for the assumption that the observed explicit memory bias is not due to a selective processing of negatively evaluated material in (relatively) anxious individuals, but reflects a concern-related bias toward food-, weight-, and shape-related information. Hence, the data corroborate the prediction of King et al. (1991) and Vitousek and Hollon (1990, p. 203) that patients with anorexia nervosa should display a selective memory for anorexia-related information, and thus indicate that information related to weight, shape, and food is well embedded within the memory structures of patients with anorexia nervosa.

With the use of Graf and Mandler's (1984) terminology, the data from the cued-recall task demonstrate a strong elaboration of anorectic concepts, which seems to be absent in nondieting controls. The conscious ruminations about topics such as appearance and weight, in which people with anorexia are so frequently engaged, undoubtedly lead to the formation of strong associative links between these anorexia-related concepts and many other (often neutral) memory representations. These elaborations are able to act as mnemonic cues to retrieve and activate the information about weight, shape, or food. And as these 
weight-related schemata are closely linked to views of the self (self-schemata; Vitousek \& Hollon, 1990), stronger elaboration implies higher probabilities of activation of the characteristic concerns about shape and weight and their relation to self-worth. So, in a fashion similar to what is described in the context of depression (Williams et al., 1988), the anorexia-related selfschemata might be implicated in the maintenance of the disorder. It is, however, still unclear what role (if any) these schemata play in the etiology of anorexia nervosa.

Although a priori contrasts for the word completion scores revealed that patients with anorexia nervosa completed significantly more word stems for primed AR words than for primed $\mathrm{Nt}$ control words, a similar trend in the same direction was present for the unprimed word completions. Subsequent analyses on primed-unprimed difference scores revealed no significant benefit of recent exposure for AR words as compared with $\mathrm{Nt}$ words. For this reason, we cannot conclude that an implicit memory bias for anorexia-related materials was present in the group of patients with anorexia nervosa.

From the perspective of the model presented by Williams et al. (1988), the present data provide support for a solid elaboration of memory representations concerning anorexia-related information in patients with anorexia nervosa, but not for their relatively higher integration (accessibility). Given that implicit memory for a stimulus is based on its integration (Mathews et al., 1989), the absence of this implicit memory effect is at odds with what should be expected from the Stroop literature, as the performance on the Stroop tasks is supposed to rely on the same process of stimulus integration (Williams et al., 1988). Indeed, as Stroop interference for anorexia-related stimuli in persons with anorexia nervosa is a quite a robust phenomenon, one should have expected an implicit memory bias rather than an explicit memory bias in the present group of patients with anorexia nervosa.

One possible explanation for the absence of such an implicit memory bias might be found in our choice of stimulus materials. As was the case in many previous studies, the set of anorexiarelated stimuli in this study consisted of words relating to parts of the body (e.g., thighs), body shape (e.g., thin), and weight (e.g., kilo), as well as words relating to food (e.g., chocolate) or eating of food (e.g., breakfast). Although Stroop interference effects have been observed for both body- and food-related words in patients with anorexia nervosa (e.g., Ben-Tovim \& Walker, 1991; Green et al., 1994; Long et al., 1994), there is some evidence that stronger effects can be obtained for food words than for body words in this group (e.g., Channon et al., 1988; Perpiña et al., 1993). This is consistent with the suggestion of Cooper and Fairburn (1992a) that patients with anorexia nervosa are most concerned about eating, whereas bulimia nervosa patients are more concerned with body weight and appearance. Hence, as they are possibly more concern-related for patients with anorexia nervosa, the use of word stems of foodrelated words alone would perhaps provide a more sensitive measure of implicit memory bias in patients with anorexia nervosa.

Nevertheless, we have rather strong evidence that not only the words related to food from our sample of 24 AR words (see Appendix ) are related to the concerns of patients with anorexia nervosa. In an additional rating study, we obtained anorexia- relatedness ratings for the 96 words used in the present experiment by a separate group of 10 patients ( 2 male, 8 female) with anorexia nervosa $(1=$ not at all related to anorexia nervosa, $10=$ very related to anorexia nervosa). The results showed that the anorexia nervosa words were rated as considerably more anorexia related $\left(M_{\mathrm{AR}}=8.19\right)$ than positive $\left(M_{\mathrm{P}}=1.13\right)$, negative $\left(M_{\mathrm{N}}=0.83\right)$, or neutral words $\left(M_{\mathrm{Nt}}=0.77\right), t(46)$ $>13.5, p<.0001$, for all three comparisons, whereas there were no differences in anorexia nervosa relatedness between the last three word types: for all comparisons, $t(46)<1$, ns. Next, the group of 24 AR words was subdivided on a post hoc basis into categories of words relating to food (candy, chocolate, cake, food, breakfast, supper, meal), body-related words (hips, breasts, thighs, belly, thin, body, appearance), and words related to body weight (balance, kilo, diet, fast, calorie, gram). Results indicated that the patients did not rate these three word categories significantly different for anorexia relatedness ( $M_{\text {food }}$ $=8.84, M_{\text {Body }}=8.71, M_{\text {weight }}=9.17$, all $\left.t \mathrm{~s}<1.25, n s\right)$. These data imply that not only the food words but also most of the AR words used in the present study were related to the specific concerns of the patients. So, it does not seem likely that the absence of an implicit memory bias for AR words should be attributed to a lack of concern relatedness for some categories of these words. Furthermore, it is not impossible to obtain a memory bias using a mixed set of body and food words, as shown by the strong explicit memory bias in this study.

Another explanation for the unexpected absence of an implicit memory bias, given the robust evidence for anorexia-related Stroop interference, is based on the idea that the word stem completion task might not be an ideal method for assessing implicit memory biases for semantically meaningful stimuli. Using a word stem completion task in a recent study with anxious patients, Mathews et al. (1995) also observed an absence of implicit memory bias in the presence of a significant emotional Stroop interference. These results, together with the results from the present study, strongly suggest that the performance on the word stem completion task and on the mentioned Stroop tasks are differentially influenced by processes other than the process of integration. In fact, there is increasing evidence that both implicit and explicit memory tasks do not provide pure measures of implicit and explicit processes (Jacoby, 1991). Most tasks probably rely on different types of processing (activation vs. elaboration; data driven vs. conceptual processing; see Roediger, 1990). In this sense, it would be good if future research on implicit memory bias in patients with anorexia nervosa would make use of other measures of implicit memory. Two possible alternatives are the primed lexical-decision task (Bradley et al., 1995 ) or the conceptually driven implicit memory task used by Watkins, Vache, Verney, Mathews, and Muller (1996). In both studies, an implicit memory bias for negatively valenced stimuli could be demonstrated in groups of depressed persons. This was quite surprising because previous studies, which used word completion tasks (Denny \& Hunt, 1992; Watkins et al., 1992), could not demonstrate a similar implicit memory bias.

On the other hand, one could argue that Stroop interference might not only arise through fully integrated memory representations but can also originate from elaborative processes. ${ }^{3}$ In-

\footnotetext{
${ }^{3}$ This possibility was suggested to us by one of the reviewers.
} 
deed, if there exist strong associations between memory representations, the activation of one concept could give rise to a temporary activation (or integration ) of the associated representations, which in turn could lead to stronger interference effects in a Stroop task. If it is true that the selective Stroop interference for AR words in patients with anorexia nervosa is (partially) based on elaborative processes, this (a) would correspond with our observation of a strong explicit memory bias and (b) would make the absence of an implicit memory bias given the strong evidence for selective Stroop interference less peculiar.

Given that Stroop and memory tasks probably do not provide pure measures of integration or elaboration, future research should be directed at disentangling implicit and explicit memory processes. A feasible route can be found in manipulating both encoding and testing conditions (Eysenck \& Byrne, 1994; Roediger, 1990). In the case of assessing implicit memory, for example, the strongest evidence for an activation-based implicit memory bias would stem from a study in which an encoding task and a memory task are used that do not rely on elaboration. A second possibility would be to make use of the process dissociation procedure, which has been proposed by Jacoby (1991), as a way to unravel the relative contributions of implicit and explicit processes in memory tasks.

Finally, we would like to stress that the observed explicit memory effect is in line with the idea that selective processing biases are content specific (Mathews \& MacLeod, 1994; Williams, Mathews, \& MacLeod, 1996) and related to the current concerns of the person (Klinger, 1996). Research in the domain of emotional disorders, for example, has demonstrated that attentional effects are greater when emotional stimuli match the domain of greatest concern to that individual. Patients with panic disorder, for example, show interference effects in a modified Stroop task for words that describe physical symptoms or their feared consequences but not for other emotional words (McNally, Riemann, Louro, Lukach, \& Kim, 1992). Similar content specificity effects have been observed for other anxiety disorders and other research methods (see Mathews \& MacLeod, 1994, p. 37). In a study by Mathews and Klug (1993) with patients with anxiety disorder, interference effects were even observed for positive words as long as they were related to the concerns of the patients. These data, together with the present results, suggest that it is the current domain of concern that determines which information is given priority in information processing. Further investigation of the importance of concern relatedness in memory biases for groups of patients with anorexia nervosa might therefore make use of more specific sets of food-related words and body-related words. More generally, future research might be oriented toward investigating different types of processing biases (e.g., interpretation, memory, and attention) in different types of clinical populations with specific concerns (e.g., addicts and paraphiliacs). Moreover, groups of nonclinical individuals with a peculiar concern (e.g., parents of hospitalized children, tennis players during the course of a championship) deserve extensive investigation (see also Riemann \& McNally, 1995).

\section{References}

American Psychiatric Assaciation. (1987). Diagnostic and statistical manual of mental disorders (3rd ed., rev.). Washington, DC: Author.
Beck, A. T. (1976). Cognitive therapy and emotional disorders. Madison, CT: International Universities Press.

Beck, A. T., Rush, A. J., Shaw, B. F., \& Emery, G. (1979). Cognitive therapy of depression. New York: Guilford Press.

Ben-Tovim, D. I., \& Walker, M. K. (1991). Further evidence for the Stroop test as a quantitative measure of psychopathology in eating disorders. International Journal of Eating Disorders, 10, 609-613.

Ben-Tovim, D. L., Walker, M. K., Fok, D., \& Yap, E. (1989). An adaptation of the Stroop test for measuring shape and food concerns in eating disorders: A quantitative measure of psychopathology? International Journal of Eating Disorders, 8, 681-687.

Bower, G. H. (1981). Mood and memory. American Psychologist, 36, 129-148.

Bradley, B. P., Mogg, K., \& Williams, R. (1995). Implicit and explicit memory for emotion-congruent information in clinical depression and anxiety. Behaviour Research and Therapy, 33, 755-770.

Butow, P., Beumont, P, \& Touyz, S. (1993). Cognitive processes in dieting disorders. International Journal of Eating Disorders, 14, 319329.

Channon, S., Hemsley, D., \& de Silva, P. (1988). Selective processing of food words in anorexia nervosa. British Journal of Clinical Psychology, 27, 259-260.

Clark, D. A., Feldman, J., \& Channon, S. (1989). Dysfunctional thinking in anorexia and bulimia nervosa. Cognitive Therapy and Research, 13, 377-387.

Cooper, M. J., \& Fairburn, C. G. (1992a) . Selective processing of eating, weight and shape related words in patients with eating disorders and dieters. British Journal of Clinical Psychology, 31, 363-365.

Cooper, M. J., \& Fairburn, C. G. (1992b). Thoughts about eating, weight and shape in anorexia nervosa and bulimia nervosa. Behaviour Research and Therapy, 30, 501-511.

Denny, E. B., \& Hunt, R. R. (1992). Affective valence and memory in depression: Dissociation of recall and fragment completion. Journal of Abnormal Psychology, 101, 575-580.

Eysenck, M. W., \& Byrne, A. (1994). Implicit memory bias, explicit memory bias, and anxiety. Cognition and Emotion, 8, 415-431.

Garner, D. M., \& Bemis, K. (1982). A cognitive-behavioural approach to anorexia nervosa. Cognitive Therapy and Research, 6, 1-27.

Garner, D. M., \& Garfinkel, P. E. (1979). The Eating Attitudes Test: An index of the symptoms of anorexia nervosa. Psychological Medicine, 9, 273-279.

Garner, D. M., Olmsted, M. P., \& Polivy, J. (1983). Development and validation of a multidimensional eating disorder inventory for anorexia nervosa and bulimia. International Journal of Eating Disorders, 2, $15-34$.

Graf, P., \& Mandler, G. (1984). Activation makes a word more accessible, but not necessarily more retrievable. Journal of Verbal Learning and Verbal Behaviour, 23, 553-568.

Green, M. W., McKenna, F. P., \& de Silva, M. S. L. (1994). Habituation patterns to colour naming of eating-related stimuli in anorexics and non-clinical controls. British Journal of Clinical Psychology, 33, 499. 508.

Hermans, D. (1994). De Zelf-Beoordelings-Vragenlijst (ZBV) IThe State-Trait Anxiety Inventory, Dutch adaptation ]. Gedragstherapie, 27, 145-148.

Hermans, D., \& De Houwer, J. (1994). Affective and familiarity ratings for 760 Dutch words. Psychologica Belgica, 34, 115-139.

Herziene woordenlijst van de Nederlandse taal [Revised wordlist of the Dutch language]. (1990). The Hague, The Netherlands: SDU uitgeverij.

Jacoby, L. J. (1991) . A process dissociation framework: Separating automatic from intentional uses of memory. Journal of Memory and Language, 30, 513-541.

King, G. A., Polivy, J., \& Herman, C. P. (1991). Cognitive aspects of 
dietary restraint: Effects on person memory. International Joumal of Eating Disorders, 10, 313-321.

Klinger, E. (1996). Theories of thought flow: Points of kinship and fertile contrasts. In R. S. Wyer, Jr. (Ed.), Advances in social cognition: Vol. LX. Ruminative thoughts (pp. 107-120). Hillsdale, NJ: Erlbaum.

Long, C. G., Hinton, C., \& Gillespie, N. K. (1994). Selective processing of food and body size words: Application of the Stroop test with obese restrained eaters, anorexics, and normals. International Journal of Eating Disorders, 15, 279-283.

MacLeod, C. (1990). Mood disorders and cognition. In M. W. Eysenck (Ed.), Cognitive psychology: An international review (pp. 9-56). Chichester, England: Wiley.

MacLeod, C., Mathews, A., \& Tata, P. (1986). Attentional bias in emotional disorders. Journal of Abnormal Psychology, 95, 15-20.

MacLeod, C., \& McLaughlin, K. (1995). Implicit and explicit memory bias in anxiety: A conceptual replication. Behaviour Research and Therapy, 33, 1-14.

Mathews, A., \& Klug, F. (1993). Emotionality and interference with colour-naming in anxiety. Behaviour Research and Therapy, 31, 5762.

Mathews, A., \& MacLeod, C. (1985). Selective processing of threat cues in anxiety states. Behaviour Research and Therapy, 23, 563569.

Mathews, A., \& MacLeod, C. (1994). Cognitive approaches to emotion and emotional disorders. Annual Review of Psychology, 45, 25-50.

Mathews, A., Mogg, K., Kentish, J., \& Eysenck, M. (1995). Effect of psychological treatment on cognitive bias in generalized anxiety disorder. Behaviour Research and Therapy, 33, 293-303.

Mathews, A., Mogg, K., May, J., \& Eysenck, M. (1989). Implicit and explicit memory bias in anxiety. Journal of Abnormal Psychology, 98, 236-240.

McNally, R. J., Riemann, B. C., Louro, C. E., Lukach, B. M., \& Kim, E. (1992). Cognitive processing of emotional information in panic disorder. Behaviour Research and Therapy, 30, 143-149.

Mizes, J. S., \& Klesges, R. C. (1987). Validity, reliability, and factor structure of the Anorectic Cognitions Questionnaire. Paper presented at the annual convention of the Association for the Advancement of Behavior Therapy, Boston.

Mogg, K., Mathews, A., May, J., Grove, M., Eysenck, M., \& Weinman, J. (1991). Assessment of cognitive bias in anxiety and depression using a colour perception task. Cognition and Emotion, 5, 221-238.

Mogg, K., Mathews, A., \& Weinman, J. (1987). Memory bias in clinical anxiety. Journal of Abnormal Psychology, 96, 94-98.

Perpiñá, C., Hemsley, D., Treasure, J., \& de Silva, P. (1993). Is the selective information processing of food and body words specific to patients with eating disorders. International Journal of Eating Disorders, 14, 359-366.

Power, M. J. (1991). Cognitive science and behavioural psychotherapy: Where behaviour was, there shall cognition be? Behavioural Psychotherapy, 19, 20-41.

Richards, A., \& French, C. C. (1991). Effects of encoding and anxiety on implicit and explicit memory performance. Personality and Individual Differences, 12, 131-139.
Riemann, B. C., \& McNally, R. J. (1995). Cognitive processing of personally relevant information. Cognition and Emotion, 9, 325-340.

Roediger, H. L., III. ( 1990). Implicit memory: Retention without remembering. American Psychologist, 45, 1043-1056.

Sebastian, S. B., Williamson, D. A., \& Blouin, D. C. (1996). Memory bias for fatness stimuli in the eating disorders. Cognitive Therapy and Research, 20, 275-286.

Spielberger, C. D., Gorsuch, R. L., Lushene, R., Vagg, P. R., \& Jacobs, G. A. (1983). Manual for the State-Trait Anxiety Inventory. Palo Alto, CA: Consulting Psychologists Press.

Stinissen, J., Willems, P. J., Coetsier, P., \& Hulsman, W. L. L. (1970). Handleiding bij de Nederlandstalige bewerking van de Wechsler Adult Intelligence Scale (W.A.I.S.) TManual of the Dutch adaptation of the Wechsler Adult Intelligence Scale (W.A.I.S.)]. Lisse, The Netherlands: Swets \& Zeitlinger

Stroop, J. R. ( 1935). Studies on interference in verbal reactions. Journal of Experimental Psychology, 18, 643-662.

Tucker, D. D., \& Schlundt, D. G. (1995). Selective information processing and schematic content related to eating behavior. Journal of Psychopathology and Behavioral Assessment, 17, 1-17.

Uit den Bogaart, P. C. (1975). Woordfrequenties in geschreven en gesproken Nederlands [Word frequencies in spoken and written Dutch]. Utrecht, The Netherlands: Oosthoek, Scheltema, \& Holkema.

Vandereycken, W. (1993). The Eating Disorder Evaluation Scale (EDES). Eating Disorders, 1, 115-122.

Van der Ploeg, H. M., Defares, P. B., \& Spielberger C. D. (1980). Handleiding bij de Zelf-Beoordelings Vragenlijst, $\mathrm{ZBV}$ [Manual for the State-Trait Anxiety Inventory; Dutch adaptation]. Lisse, The Netherlands: Swets \& Zeitlinger.

Vitousek, K., Daly, J., \& Heiser, C. (1991). Reconstructing the internal world of the eating-disordered individual: Overcoming denial and distortion in self-report. International Journal of Eating Disorders, 10, 647-666.

Vitousek, K. B., \& Hollon, S. D. (1990). The inyestigation of schematic content and processing in eating disorders. Cognitive Therapy and Research, 14, 191-214.

Walker, M. K., Ben-Tovim, D. I., Jones, S., \& Bachok, N. (1992). Repeated administration of the adapted Stroop test: Feasibility for longitudinal study of psychopathology in eating disorders. International Journal of Eating Disonders, 12, 103-105.

Walker, M. K., Ben-Tovim, D. I., Paddick, S., \& McNamara, J. (1995). Pictorial adaptation of Stroop measures of body-related concerns in eating disorders. International Journal of Eating Disorders, 17, 309311.

Watkins, P., Mathews, A. M., Williamson, D. A., \& Fuller, R. (1992). Mood congruent memory in depression: Emotional priming or elaboration ? Journal of Abnormal Psychology, 101, 581-586.

Watkins, P., Vache, K., Verney, S. P., Mathews, A., \& Muller, S. ( 1996). Unconscious mood-congruent memory bias in depression. Journal of Abnormal Psychology, 105, 34-41.

Williams, J., Mathews, A., \& MacLeod, C. (1996). The emotional Stroop task and psychopathology. Psychological Bulletin, 120, 3-24.

Williams, J., Watts, F., MacLeod, C., \& Mathews, A. ( 1988). Cognitive psychology and emotional disorders. Chichester, England: Wiley. 


\section{Appendix}

Stimulus Words in Dutch (and English Translation)

\begin{tabular}{|c|c|c|c|}
\hline Anorexia related & Positive & Negative & Neutral \\
\hline \multicolumn{4}{|c|}{ Set $A$} \\
\hline $\begin{array}{l}\text { dieet (diet) } \\
\text { buik (belly) } \\
\text { dijen (thighs) } \\
\text { maaltijd (meal) } \\
\text { mager (thin) } \\
\text { borsten (breasts) } \\
\text { heupen (hips) } \\
\text { calorie (calorie) }\end{array}$ & $\begin{array}{l}\text { zonneschijn (sunshine) } \\
\text { bloemen (flowers) } \\
\text { melodie (melody) } \\
\text { saffier (sapphire) } \\
\text { circus (circus) } \\
\text { poesje (kitten) } \\
\text { televisie (television) } \\
\text { verjaardag (birthday) }\end{array}$ & $\begin{array}{l}\text { vishaak (fishhook) } \\
\text { tandarts (dentist) } \\
\text { slijm (slime) } \\
\text { hoer (whore) } \\
\text { misdaad (crime) } \\
\text { slachting (slaughter) } \\
\text { tumor (tumor) } \\
\text { bommen (bombs) }\end{array}$ & $\begin{array}{l}\text { pool (pole) } \\
\text { raadsel (riddle) } \\
\text { mand (basket) } \\
\text { winkel (shop) } \\
\text { vodka (vodka) } \\
\text { balpen (ballpoint) } \\
\text { vijver (pond) } \\
\text { venster (window) }\end{array}$ \\
\hline \multicolumn{4}{|c|}{ Set B } \\
\hline $\begin{array}{l}\text { vasten (fast) } \\
\text { chocolade (chocolate) } \\
\text { menstruatie (menstruation) } \\
\text { ontbijt (breakfast) } \\
\text { braken (throw up) } \\
\text { uiterlijk (appearance) } \\
\text { kilo (kilo) } \\
\text { overgeven (vomit) }\end{array}$ & $\begin{array}{l}\text { broeders (brothers) } \\
\text { geschenk (gift) } \\
\text { hondje (dog) } \\
\text { vakantie (holidays) } \\
\text { bruid (bride) } \\
\text { boeket (bouquet) } \\
\text { parade (parade) } \\
\text { vlinder (butterfly) }\end{array}$ & $\begin{array}{l}\text { executie (execution) } \\
\text { kanker (cancer) } \\
\text { kerkhof (cemetery) } \\
\text { belastingen (taxes) } \\
\text { Hitler (Hitler) } \\
\text { kakkerlak (cockroach) } \\
\text { spin (spider) } \\
\text { stormen (storms) }\end{array}$ & $\begin{array}{l}\text { klooster (monastery) } \\
\text { boog (bow) } \\
\text { autobus (motorbus) } \\
\text { agentschap (agency) } \\
\text { basketbal (basketball) } \\
\text { vierkant (square) } \\
\text { staal (steel) } \\
\text { wens (wish) }\end{array}$ \\
\hline \multicolumn{4}{|c|}{ Set C } \\
\hline $\begin{array}{l}\text { voedsel (food) } \\
\text { vreetbui (overeating) } \\
\text { avondmaal (supper) } \\
\text { snoep (candy) } \\
\text { lichaam (body) } \\
\text { gram (gram) } \\
\text { weegschaal (balance) } \\
\text { taart (cake) }\end{array}$ & $\begin{array}{l}\text { dagdroom (daydream) } \\
\text { wijn (wine) } \\
\text { antilope (antelope) } \\
\text { peuter (toddler) } \\
\text { tekenfilm (cartoon) } \\
\text { geboorte (birth) } \\
\text { regenboog (rainbow) } \\
\text { wolk (cloud) }\end{array}$ & $\begin{array}{l}\text { wormen (worms) } \\
\text { gezwel (growth) } \\
\text { astma (asthma) } \\
\text { infectie (infection) } \\
\text { straling (radiation) } \\
\text { monster (monster) } \\
\text { ongeluk (misfortune) } \\
\text { moord (murder) }\end{array}$ & $\begin{array}{l}\text { klei (clay) } \\
\text { priester (priest) } \\
\text { landheer (landowner) } \\
\text { Rusland (Russia) } \\
\text { naaimachine (sewing machine) } \\
\text { trapezium (trapeze) } \\
\text { behangpapier (wallpaper) } \\
\text { trompet (trumpet) }\end{array}$ \\
\hline
\end{tabular}

Received February 2, 1995

Revision received July 22, 1997

Accepted September 3, 1997 